\title{
Melatonin counteracts cobalt nanoparticle-induced cytotoxicity and genotoxicity by deactivating reactive oxygen species-dependent mechanisms in the NRK cell line
}

\author{
YAKE LIU*, XIAOYOU YANG*, WEI WANG, XUEFEI WU, HAI ZHU and FAN LIU \\ Department of Orthopedics, The Affiliated Hospital of Nantong University, Nantong, Jiangsu 226001, P.R. China
}

Received October 24, 2016; Accepted June 9, 2017

DOI: $10.3892 / \mathrm{mmr} .2017 .7309$

\begin{abstract}
Cobalt nanoparticles (CoNPs) released from metal-on-metal implants have caused considerable concern. Oxidative stress is associated with the mechanism underlying cobalt-induced cytotoxicity and genotoxicity. The indolamine melatonin exhibits protective effects against damage induced by metals. The present study investigated the in vitro effects of melatonin on the cytotoxicity and genotoxicity induced by CoNPs. CoNPs (20-50 nm in diameter) were employed in the present study. NRK rat kidney cells were exposed to various concentrations of CoNPs for different durations. The results of the current study demonstrated that CoNPs significantly increased reactive oxygen species (ROS) production and reduced cell viability, as determined by dichlorofluorescein diacetate, and Cell Counting Kit-8 and lactate dehydrogenase leakage assays, respectively. Furthermore, western blot analysis demonstrated that CoNPs led to an increase in the ratio of Bcl-2-associated $\mathrm{X} / \mathrm{Bcl}-2$, and the expression of cleaved caspase- 3 was upregulated, which indicated increased apoptosis levels. Genotoxicity was detected by a comet assay, which revealed a significant induction in DNA damage, as determined by increases in the tail DNA \% and olive tail moment. Phosphorylated-histone H2AX foci analyses by immunofluorescence also demonstrated that CoNPs induced DNA-double strand breaks. However, cellular treatment with melatonin reduced the effects of CoNPs on NRK cells by reducing the production of ROS. The results of the present study demonstrated that CoNPs induced cytotoxicity and genotoxicity by increasing oxidative stress, and melatonin may have pharmacological potential in protecting against the damaging effects of CoNPs following total hip arthroplasty.
\end{abstract}

Correspondence to: Professor Fan Liu, Department of Orthopedics, The Affiliated Hospital of Nantong University, 19 QiXiu Road, Nantong, Jiangsu 226001, P.R. China

E-mail: liufan20142016@aliyun.com

${ }^{*}$ Contributed equally

Key words: cobalt nanoparticles, cytotoxicity, genotoxicity, oxidative stress, melatonin

\section{Introduction}

Metal-on-metal (MoM) resurfacing hip implants have received recognition since the second generation was developed in 1990. Cobalt-chromium (CoCr) alloy casting implants have exhibited numerous benefits; they reduce the risk of dislocation and maintain improved femoral loading, and reduce stress-shielding and exhibit improved wear characteristics, which contributes to joint stability and the avoidance of component impingement (1). However, potential complications due to the dissemination of metal particles in the nanometer size range, and concomitant release of ions throughout the circulation, have limited the success of such implants (2).

During revision surgeries or necropsy examinations, allochroic tissue is commonly observed around $\mathrm{CoCr}$ implants. Furthermore, certain patients experience inexplicable pain, which may be associated with the tissue damage caused by MoM hip replacements wear (3). Increasing evidence indicates that these particles, and concomitant ions, may be associated with various adverse health issues, including neurological (4) (static tremor, motor incoordination, vertigo, hearing decline and visual issues), cardiac (5) (myocardiopathy) and endocrine (6) symptoms.

A high number of these nanometer-sized particles are present, and they are phagocytosed by macrophages, which leads to the release of various types of mediators, the majority of which are free radicals (7) This reactive oxygen species (ROS) generation induced by metal nanoparticles was reported to be closely associated with apoptosis (8), which may occur via the oxidation of cellular structures and components. Ladon et al (9) reported an increase in chromosome aberrations consisting of chromosome translocations in the peripheral blood following hip arthroplasty. Similar genotoxic potential was also observed when exposed to $\mathrm{CoCr}$ nanoparticles (10). Furthermore, accumulating evidence indicates that ROS has an important role in the cytotoxicity process as well as in genotoxicity (11-13).

Melatonin, the primary product that is secreted by the pineal gland, is a ubiquitous biological signaling and functionally diverse molecule. The indolamine has been reported to be beneficial in various oxidative stress-associated diseases, including diabetes (14), retinopathy (15), cardiovascular (16) and genital (17) diseases, and cancer (18), with no toxicity cases reported. Compared with conventional antioxidants, 
such as vitamin $\mathrm{C}$ and vitamin $\mathrm{E}$, melatonin exhibits an increased ability to scavenge free radicals $(19,20)$. Limited data regarding the effects of melatonin on CoNP-induced is available. Therefore, the present study investigated whether melatonin exhibits protective effects on CoNP-induced cytotoxicity and genotoxicity in the NRK cell line.

\section{Materials and methods}

Cell culture. NRK cell line (purchased from the Type Culture Collection of the Chinese Academy of Sciences, Shanghai, China) derived from rat kidney were routinely cultured in Dulbecco's modified Eagle's medium (DMEM; Sigma-Aldrich; Merck KGaA, Darmstadt, Germany) supplemented with $10 \%$ (v/v) fetal bovine serum (Gibco; Thermo Fisher Scientific, Inc., Waltham, MA, USA) and $1 \%$ penicillin-streptomycin (penicillin, $100 \mathrm{U} / \mathrm{ml}$; streptomycin, $100 \mu \mathrm{g} / \mathrm{ml}$; Sigma-Aldrich; Merck $\mathrm{KGaA}$ ) at $37^{\circ} \mathrm{C}$ under a humidified atmosphere of $5 \% \mathrm{CO}_{2}$ in a cell culture incubator. Cells $\left(1.5 \times 10^{4}\right.$ cells/well $)$ were exposed to varying concentrations of CoNPs (diameter, 20-50 nm; Sigma-Aldrich; Merck KGaA; 10, 50, 100, 200, 400 and $500 \mu \mathrm{M})$ in media for different durations (4, 24 and $48 \mathrm{~h}$ ) for subsequent experiments at $37^{\circ} \mathrm{C}$. Cells cultured with DMEM acted as the control group. An appropriate concentration of CoNPs $\left(50 \%\right.$ inhibitory concentration, $\left.\mathrm{IC}_{50} ; 100 \mu \mathrm{M}\right)$ was selected for experiments that involved melatonin treatment. Melatonin (Sigma-Aldrich; Merck KGaA) was dissolved in dimethylsulfoxide (DMSO; Sigma-Aldrich; Merck KGaA) prior to use and was immediately added to cells at various doses $(5,10,50,100,200$ and $300 \mu \mathrm{M})$, which was maintained during treatment with CoNPs, and was also performed for various durations $(4,24$ and $48 \mathrm{~h})$ at $37^{\circ} \mathrm{C}$. DMSO was used as a vehicle and the final concentration did not exceed $0.1 \%$ (v/v) (21).

Nanoparticles. Stock solutions of CoNPs were prepared at a concentration of $100 \mathrm{mM}$ in ultrapure water. The stock solutions were sonicated intermittently six times for $30 \mathrm{~min}$, as described previously (22). The stock solutions were freshly diluted with culture medium to the test concentrations $(10,50$, $100,200,400$ and $500 \mu \mathrm{M})$.

Cell viability assay. Cell viability was detected using the Cell Counting kit-8 (CCK-8) assay (Dojindo Molecular Technologies, Inc., Kumamoto, Japan). Cells (1.5x10 4 cells/well) were plated into 96-well plates and exposed to CoNPs $(0,10$, $50,100,200,400$ or $500 \mu \mathrm{M})$ and melatonin $(0,5,10,50,100$, 200 or $300 \mu \mathrm{M}$ ) for 4,24 or $48 \mathrm{~h}$. Culture medium served as the control in each experiment. In order to investigate the effects of melatonin on the viability of NRK cells exposed to CoNPs, the cells were exposed to $100 \mu \mathrm{M}\left(\mathrm{IC}_{50}\right)$ CoNPs, and subsequently, the cells were incubated for 4,24 or $48 \mathrm{~h}$ in the presence of melatonin $(0-300 \mu \mathrm{M})$. CCK-8 solution $(10 \mu \mathrm{l})$ was added to each well of the plate for $30 \mathrm{~min}$ at $37^{\circ} \mathrm{C}$ prior to detection. The CCK-8 formazan product was measured at $450 \mathrm{~nm}$ using a microplate reader.

Lactate dehydrogenase $(L D H)$ leakage assay. The release of cytoplasmic LDH enzyme into the culture medium was determined, as previously described (13). NRK cells exposed to $100 \mu \mathrm{M}$ CoNPs were treated with melatonin $(10$ or $100 \mu \mathrm{M})$ for 4, 24 and $48 \mathrm{~h}$. Following exposure, $120 \mu \mathrm{l}$ supernatant from the centrifuged culture media were collected (200 x g for $3 \mathrm{~min}$ at room temperature). The LDH activity was assayed in $3 \mathrm{ml}$ reaction mixture with $100 \mu \mathrm{l}$ pyruvic acid $(2.5 \mathrm{mg} / \mathrm{ml}$ phosphate buffer) and $100 \mu \mathrm{l}$ reduced nicotinamide adenine dinucleotide (NADH; $2.5 \mathrm{mg} / \mathrm{ml}$ phosphate buffer). The remaining volume was adjusted with phosphate buffer $(0.1 \mathrm{M}$; $\mathrm{pH}$ 7.4). The rate of NADH oxidation was determined at a wavelength of $490 \mathrm{~nm}$ using a microplate reader. The amount of $\mathrm{LDH}$ released was expressed as $\mathrm{LDH}$ activity (IU/1) in culture media.

Western blot assay. Following CoNP $(100 \mu \mathrm{M})$ exposure, cells treated with control and melatonin $(10$ or $100 \mu \mathrm{M})$ for $24 \mathrm{~h}$ were harvested, pelleted ( $200 \mathrm{x}$ g for $3 \mathrm{~min}$ at room temperature and lysed by adding ice-cold radioimmunoprecipitation assay lysis buffer containing $50 \mathrm{mM}$ Tris- $\mathrm{HCl}$ (pH 7.4), $150 \mathrm{mM} \mathrm{NaCl}$, 2 mM EDTA, $0.1 \%$ Triton-X-100, 10\% sodium deoxycholate, $10 \%$ SDS, $1 \mathrm{mM} \mathrm{NaF}$ and protease inhibitor cocktail. Protein concentrations were determined by the Bradford method. Total protein $(30 \mu \mathrm{g})$ was resolved by 10 and $12 \%$ SDS-PAGE and transferred onto polyvinylidene fluoride membranes. The blotted membrane was blocked with $5 \%$ non-fat dry milk for $2 \mathrm{~h}$ at room temperature and incubated overnight at $4{ }^{\circ} \mathrm{C}$ with specific antibodies against Bcl-2-associated X (Bax; 1:800; cat. no. D3R2M), Bcl-2 (1:800; cat. no. D17C4), cleaved caspase-3 (1:500; cat. no. 9654) and GAPDH (1:1,000; cat. no. 8884). All primary antibodies were obtained from Cell Signaling Technology, Inc. (Danvers, MA, USA). The blots were subsequently incubated with horseradish peroxidase-conjugated secondary antibody (1:1,000; cat. no. A0545; Sigma-Aldrich; Merck $\mathrm{KGaA}$ ) for $2 \mathrm{~h}$ at room temperature and bands were detected by enhanced chemiluminescence using SuperSignal West Femto Chemiluminescent Substrate (Pierce; Thermo Fisher Scientific, Inc.). Densitometric analysis was performed by ImageJ software (version 1.47; National Institutes of Health, Bethesda, MD, USA).

Comet assay. DNA damage detected by comet assay was an adaptation described by Uzar et al (23). Cells ( $2 \times 10^{4}$ cells/well) exposed to CoNPs were co-incubated with melatonin (10 or $100 \mu \mathrm{M}$ ) for 4, 24 or $48 \mathrm{~h}$, and washed with PBS, trypsinized, centrifuged at $200 \mathrm{x}$ g for $3 \mathrm{~min}$ at room temperature and resuspended in $0.5 \mathrm{ml}$ PBS. Briefly, $100 \mu \mathrm{l}$ cells were mixed with $100 \mu \mathrm{l}$ pre-warmed low-melting point agarose $(0.65 \%$ in PBS), layered on normal-melting point agarose $(1.5 \%$ in distilled water) precoated microscope slides and covered with a coverslip. Slides were placed in a refrigerator for solidification, coverslips were removed and slides were incubated for $1 \mathrm{~h}$ at $4^{\circ} \mathrm{C}$ in lysis solution $(2.5 \mathrm{M} \mathrm{NaCl}, 100 \mathrm{mM}$ EDTA and $10 \mathrm{mM}$ Tris-HCl, pH 10) with $10 \%$ DMSO and $1 \%$ Triton-X-100. DNA was denatured for $20 \mathrm{~min}$ in cold-fresh electrophoresis buffer (0.3 M NaOH, $1 \mathrm{mM}$ EDTA, pH 13) at $4^{\circ} \mathrm{C}$ and electrophoresis was performed at $4^{\circ} \mathrm{C}$ for $20 \mathrm{~min}(20 \mathrm{~V} / 300 \mathrm{~mA})$. Following electrophoresis, slides were neutralized with $0.4 \mathrm{M}$ Tris- $\mathrm{HCl}$ buffer ( $\mathrm{pH} \mathrm{7.5)} \mathrm{three} \mathrm{times} \mathrm{for} 5 \mathrm{~min}$. Cells were scored under a fluorescent microscope at x400 magnification by using ImageJ software (version 1.47) immediately after DNA was stained with ethidium bromide $(20 \mu \mathrm{g} / \mathrm{ml})$ for $15 \mathrm{~min}$ at room 

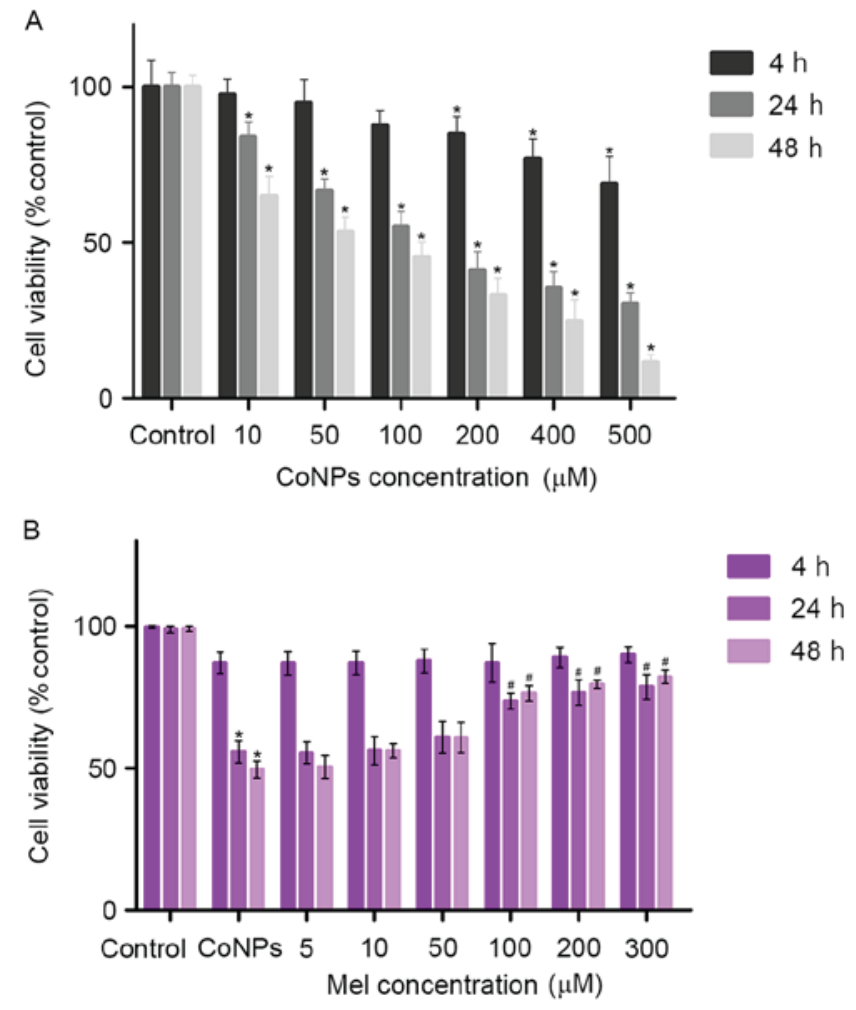

Figure 1. Changes in cell viability of NRK cells following CoNP and melatonin treatment. (A) Viability of NRK cells exposed to 0-500 $\mu \mathrm{M}$ CoNPs for 4,24 and $48 \mathrm{~h}$, as determined by a Cell Counting kit- 8 assay. (B) Effects of 0-300 $\mu \mathrm{M}$ melatonin on cell viability in NRK cells when exposed to $100 \mu \mathrm{M}$ CoNPs for 4, 24 and $48 \mathrm{~h}$ (B). Data are presented as the mean $\pm \mathrm{stan}$ dard deviation of three independent experiments performed in triplicate. ${ }^{*} \mathrm{P}<0.05$ vs. control and ${ }^{\#} \mathrm{P}<0.05$ vs. CoNPs group at same time point. CoNPs, cobalt nanoparticles; mel, melatonin.

temperature. At least 100 cells were scored per concentration. The percentage tail DNA, tail length and olive tail moment (OTM; product of tail length and the fraction of total DNA in the tail) was analyzed.

Immunostaining of phosphorylated-histone $2 A X(\gamma H 2 A X)$ foci. $\gamma \mathrm{H} 2 \mathrm{AX}$ foci were used as a marker of DNA-double strand breaks (DSBs). NRK cells $\left(1 \times 10^{5}\right.$ cells/well) were cocultured with $100 \mu \mathrm{M} \mathrm{CoNPs}$ and melatonin $(10$ or $100 \mu \mathrm{M})$ for 4,24 and $48 \mathrm{~h}$. Cells were subsequently reseeded on coverslips in 6-well plates, fixed for 15 min with $4 \%$ paraformaldehyde at $4^{\circ} \mathrm{C}$ and washed with PBS. Following treatment with $0.2 \%$ Triton-X-100 for $15 \mathrm{~min}$ at $4{ }^{\circ} \mathrm{C}$, blocking was performed by incubation for $90 \mathrm{~min}$ at room temperature with blocking solution containing $3 \%$ (v/v) bovine serum albumin (Sigma-Aldrich; Merck $\mathrm{KGaA}$ ) in PBS. Rabbit polyclonal antibody (1:500 in blocking solution; cat. no. ADI-905-771-100; Alexis Biochemicals; Enzo Life Sciences, Inc., Farmingdale, NY, USA) against human $\gamma \mathrm{H} 2 \mathrm{AX}$ was incubated with cells overnight at $4^{\circ} \mathrm{C}$. The following day, the coverslips were washed three times with PBS and secondary donkey anti-rabbit Cy3-labeled antibody (1:500 in blocking solution; cat. no. AP182C; Chemicon; EMD Millipore, Billerica, MA, USA) was incubated with cells for $60 \mathrm{~min}$ at $37^{\circ} \mathrm{C}$. The coverslips were finally inverted onto pre-cleaned dry slides with a droplet (30 $\mu$ l per coverslip) of DAPI-Vectashield ${ }^{\circledR}$ Antifade Mounting Medium (Vector Laboratories, Inc., Burlingame, CA, USA) and edges were sealed with clear nail polish. All slides were examined using an inverted fluorescence microscope (magnification, $x 40$ ). The protocol described in the present study is an adaptation of the protocol described by Tsaousi et al (24). For quantitative analysis, foci were counted using ImageJ software (version 1.47). For each sample at least 60 cells were analyzed.

Determination of intracellular ROS content. Intracellular ROS levels were detected based on the ROS-mediated oxidation of nonfluorescent dichlorofluorescin (DCFH), which leads to the production of fluorescent dichlorofluorescein (DCF). DCFH-diacetate (DCFH-DA) passively diffuses into cells and esterases deacetylate DCFH-DA, leading to the formation of nonfluorescent DCFH. When ROS is present, DCFH undergoes a reaction with ROS that leads to the production of fluorescent DCF, which cannot exit cells. Therefore, the level of fluorescence is associated with ROS levels within cells (25). After cells $\left(2 \times 10^{4}\right.$ cells/well) were exposed to $100 \mu \mathrm{M}$ CoNPs in 96-well plates, various concentrations (10 or $100 \mu \mathrm{M})$ of melatonin were added for 4, 24 and $48 \mathrm{~h}$. Cells were subsequently incubated with DCFH-DA (10 $\mu \mathrm{M}$; Nanjing Jiancheng Bioengineering Institute, Nanjing, China) at $37^{\circ} \mathrm{C}$ for $20 \mathrm{~min}$. The fluorescence of the cells in each well was measured at an emission wavelength of $530 \mathrm{~nm}$ and an excitation wavelength of $485 \mathrm{~nm}$ using microplate reader. ROS levels were expressed as a percentage of the control.

Statistical analysis. Data are presented as the mean \pm standard deviation. Significant differences were evaluated by one-way analysis of variance followed by Dunnett's post hoc test. Statistical analyses were performed with SAS 9.1 statistical software (SAS Institute, Cary, NC, USA). P<0.05 was considered to indicate a statistically significant difference.

\section{Results}

CCK-8 and LDH leakage assays. Cell viability was assessed after 4, 24 and $48 \mathrm{~h}$ exposure to 0, 10, 50, 100, 200, 400 and 500 CoNPs, and significant decreases in cell viability were observed in the 24 and $48 \mathrm{~h}$ treatment groups, even at low concentrations of CoNPs, compared with the control group at the same time point $(\mathrm{P}<0.05$; Fig. 1A). At concentrations of 200,400 and $500 \mu \mathrm{M}$, the cell viability in the $4 \mathrm{~h}$ exposure group was significantly reduced compared with the $4 \mathrm{~h}$ control group $(\mathrm{P}<0.05$; Fig. 1A).

No significant protective effects were observed when cells were treated with 5,10 or $50 \mu \mathrm{M}$ melatonin (Fig. 1B). However, significant increases in cell viability were observed in the 24 and $48 \mathrm{~h}$ treatment groups when treated with 100 , 200 and $300 \mu \mathrm{M}$ melatonin $(\mathrm{P}<0.05$; Fig. 1B), compared with the CoNP-only treatment group $(100 \mu \mathrm{M})$. To verify the effective concentration of melatonin, $10 \mu \mathrm{M}$ was selected as the low concentration and $100 \mu \mathrm{M}$ as the high concentration for subsequent experiments.

The protective effects of melatonin against reductions in cell viability induced by CoNPs observed in the CCK-8 assay were also supported by similar results obtained from the LDH leakage assay (Fig. 2). 


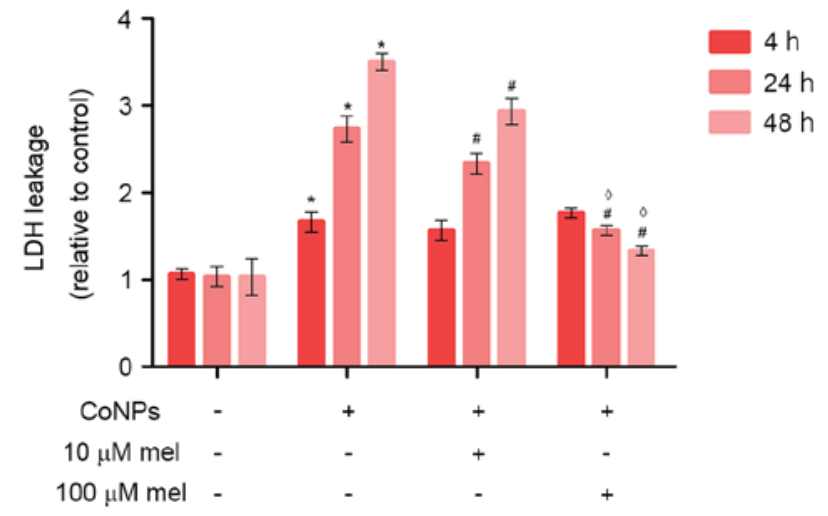

Figure 2. Analysis of cytotoxicity detected by LDH leakage in NRK cells following exposure to $100 \mu \mathrm{M}$ CoNPs and melatonin (10 and $100 \mu \mathrm{M})$ for 4,24 and $48 \mathrm{~h}$. Data are presented as the mean \pm standard deviation of three independent experiments performed in triplicate. ${ }^{*} \mathrm{P}<0.05$ vs. control, ${ }^{\#} \mathrm{P}<0.05$ vs. CoNPs group and ${ }^{\diamond} \mathrm{P}<0.05$ vs. $10 \mu \mathrm{M}$ melatonin at same time point. $\mathrm{LDH}$, lactate dehydrogenase; CoNPs, cobalt nanoparticles; mel, melatonin.

Western blot analysis. Western blot analysis was performed to investigate alterations in the expression of proteins associated with apoptosis. The results of the group treated with $100 \mu \mathrm{M}$ CoNPs and $100 \mu \mathrm{M}$ melatonin for $24 \mathrm{~h}$ revealed that the expression of Bax was decreased and Bcl-2 increased (Fig. 3A), which resulted in a significant reduction in the ratio of $\mathrm{Bax} / \mathrm{Bcl}-2$ compared with the CoNP-only treatment group ( $\mathrm{P}<0.05$; Fig. $3 \mathrm{~B})$. Similarly, significantly reduced expression of cleaved caspase-3 was observed in the $100 \mu \mathrm{M}$ melatonin treatment compared with the CoNP-only group (Fig. 3C and D). The $10 \mu \mathrm{M}$ melatonin treatment group exhibited no significant protective effect on the $\mathrm{Bax} / \mathrm{Bcl}-2$ ratio or cleaved caspase-3 levels (Fig. 3).

Comet assay. Genotoxicity was observed as cell DNA migrated towards the anode more rapidly following exposure to CoNPs compared with the control. Genotoxicity was revealed by increases in OTM and tail DNA \%. Treatment with melatonin (10 and $100 \mu \mathrm{M}$ ) significantly decreased OTM and tail DNA $\%$ in the 24 and $48 \mathrm{~h}$ groups, and reduced DNA damage was observed when treated with $100 \mu \mathrm{M}$ melatonin compared with $10 \mu \mathrm{M}$ melatonin (Fig. 4; $\mathrm{P}<0.05$ ). However, $4 \mathrm{~h}$ coculture demonstrated no significant protective effects.

Immunostaining of $\gamma \mathrm{H} 2 \mathrm{AX}$ foci. To obtain increased insight into the potential mechanisms underlying the protective effect of melatonin on CoNP-induced genotoxicity, the presence of DNA-DSBs was determined by $\gamma \mathrm{H} 2 \mathrm{AX}$ foci staining. DNA damage increased strongly at $24 \mathrm{~h}$ of exposure to $100 \mu \mathrm{M}$ CoNPs, however, foci counts were decreased at $48 \mathrm{~h}$ (Fig. 5). When NRK cells were incubated with CoNPs in the presence of $100 \mu \mathrm{M}$ melatonin, the indolamine significantly reduced the foci counts compared with the CoNP-only group at 24 and $48 \mathrm{~h}(\mathrm{P}<0.05$; Fig. 5). Treatment with $100 \mu \mathrm{M}$ melatonin for $4 \mathrm{~h}$ demonstrated no significant effects on foci counts compared with the CoNP-only treatment group. The effects of $10 \mu \mathrm{M}$ melatonin on foci counts were markedly lower compared with the $100 \mu \mathrm{M}$ melatonin treatment group (Fig. 5).

Determination of intracellular ROS content. The effect of melatonin to protect against oxidative stress was investigated by measuring the levels of intracellular ROS reduction. After NRK cells were exposed to $100 \mu \mathrm{M}$ CoNPs, the results demonstrated that ROS production significantly increased compared with the control group $(\mathrm{P}<0.05$; Fig. 6). The green color indicates the fluorescence of ROS production (Fig. 6A-D 24 h). Quantitative analysis indicated that ROS production significantly increased to $1.29,2.07$ and 3.78 fold that of controls following exposure to CoNPs for 4, 24 and $48 \mathrm{~h}$, respectively (Fig. 6E-G). However, treatment with melatonin $(10$ and $100 \mu \mathrm{M})$ reduced ROS generation in a concentration-dependent manner compared with the positive control group. Melatonin reduced ROS generation strongly at a maximum of $63 \%$ at $48 \mathrm{~h}$ (Fig. 6G).

\section{Discussion}

A number of studies have been performed to investigate and identify methods of reducing the toxicity induced by CoNPs $(26,27)$. However, to the best of our knowledge, no confirmed solutions have been identified currently. Our previous studies $(28,29)$ indicated that cobalt exposure induced significant cytotoxicity and genotoxicity in vitro, and the mechanism may be ROS-dependent $(8,12,30)$. Notably, a previous study demonstrated that metal ions released from nanoparticles lead to less damage compared with nanoparticles (31). Although melatonin has been reported to exert protective effects against oxidative stress, predominantly induced by ions $(25,32,33)$, limited data is available regarding the therapeutic effects of melatonin on the adverse biological reactions associated with CoNPs released from MoM implants. Therefore, the present study investigated the in vitro effects of melatonin on CoNP-induced cytotoxicity and genotoxicity in NRK cells.

Reduced viability of CoNP-treated cells compared with control cells observed in the present study may be an indicator for apoptosis. The CCK- 8 assay was performed to assess the cytotoxicity of CoNPs, and the results demonstrated a timeand dose-dependent effect of CoNPs in NRK cells compared with controls. Based on the results, the $\mathrm{IC}_{50}$ value was calculated and $100 \mu \mathrm{M}$ CoNPs was used as the positive control for subsequent experiments. Furthermore, $10 \mu \mathrm{M}$ melatonin was selected as the low concentration and $100 \mu \mathrm{M}$ melatonin as the high concentration to investigate the effects of this melatonin on CoNP-induced damage. The results of the CCK-8 assay demonstrated that treatment with melatonin reduced CoNP-induced reductions in cell viability. Results of the LDH leakage assay confirmed that melatonin exhibited a protective effect on maintaining membrane integrity.

The ratio of $\mathrm{Bax} / \mathrm{Bcl}-2$, which was upregulated in cells exposed to CoNPs in the present study, is an established molecular biomarker associated with the apoptotic mechanism (34). The results of western blot analysis demonstrated that melatonin reduced the ratio of $\mathrm{Bax} / \mathrm{Bcl}-2$ compared with the CoNP-only group, which indicates a potential anti-apoptotic function. We hypothesized that the mitochondrial pathway may have a crucial role in the anti-apoptotic effect of melatonin on CoNP-induced apoptosis. Caspase-3 is reported to be essential in the apoptotic pathway (35), and the expression of cleaved caspase- 3 was downregulated by melatonin in the present study compared with the CoNP-only 

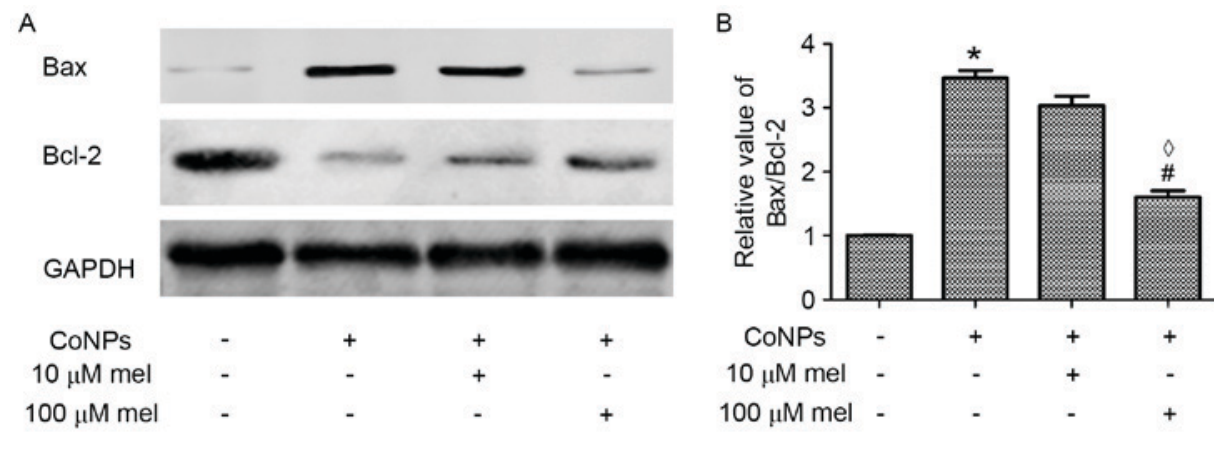

C

D
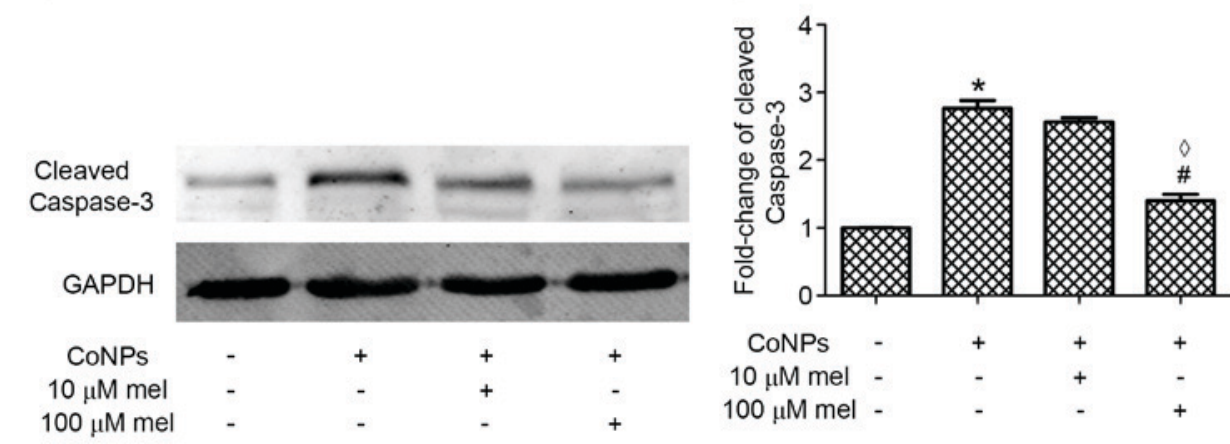

Figure 3. Western blot analysis of apoptosis-associated proteins in NRK cells treated with $100 \mu \mathrm{M}$ CoNPs and melatonin (10 and $100 \mu \mathrm{M})$ for 24 h. GAPDH was used as an internal control. (A) Representative western blot and (B) densitometric analysis of Bax and Bcl-2 protein levels. (C) Representative western blot and (D) densitometric analysis of cleaved caspase-3 protein levels. ${ }^{*} \mathrm{P}<0.05$ vs. control, ${ }^{\#} \mathrm{P}<0.05$ vs. CoNPs group and ${ }^{\ominus} \mathrm{P}<0.05$ vs. $10 \mu \mathrm{M}$ melatonin. CoNPs, cobalt nanoparticles; Bax, Bcl-2-associated X; mel, melatonin.

$4 \mathrm{~h}$

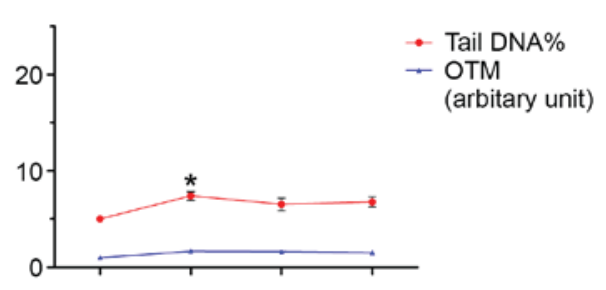

$24 \mathrm{~h}$

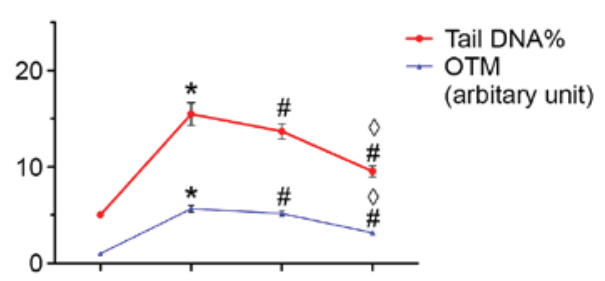

$48 \mathrm{~h}$

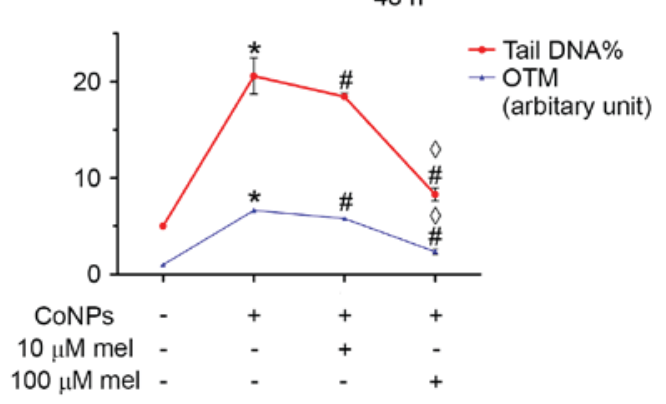

Figure 4. DNA damage was assessed by a comet assay in NRK cells following exposure to $100 \mu \mathrm{M}$ CoNPs and melatonin $(10$ and $100 \mu \mathrm{M})$ for 4,24 and 48 h. ${ }^{*} \mathrm{P}<0.05$ vs. control, ${ }^{\#} \mathrm{P}<0.05$ vs. CoNPs group and ${ }^{\diamond} \mathrm{P}<0.05$ vs. $10 \mu \mathrm{M}$ melatonin. CoNPs, cobalt nanoparticles; OTM, olive tail moment; mel, melatonin.
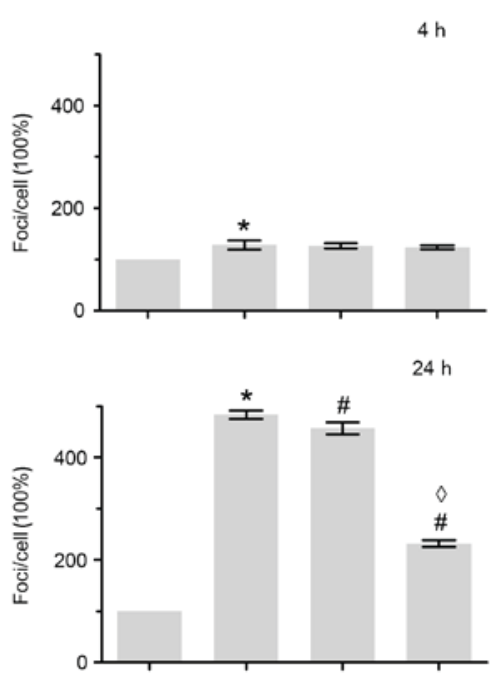

$48 \mathrm{~h}$

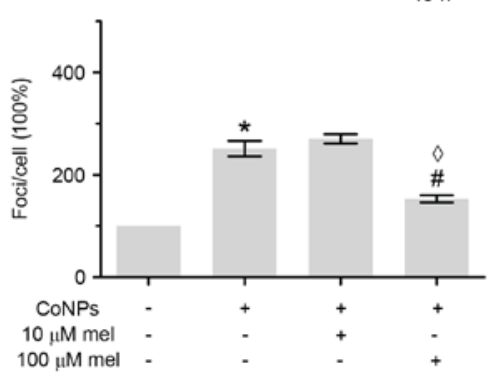

Figure 5. DNA-double strand break analysis following CoNPs exposure. NRK cells were exposed to $100 \mu \mathrm{M}$ CoNPs and melatonin (10 and $100 \mu \mathrm{M})$ for 4, 24 and $48 \mathrm{~h}$. DNA-double strand breaks were quantified by counting the number of phosphorylated-histone $2 \mathrm{AX}$ foci per cell using ImageJ software. ${ }^{*} \mathrm{P}<0.05$ vs. control, ${ }^{\#} \mathrm{P}<0.05$ vs. CoNPs group and ${ }^{\bullet} \mathrm{P}<0.05$ vs. $10 \mu \mathrm{M}$ melatonin. CoNPs, cobalt nanoparticles; mel, melatonin. 

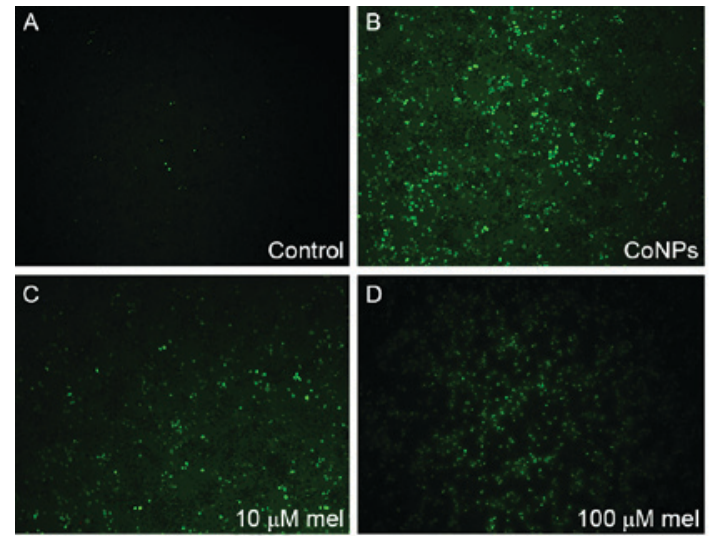

$\mathrm{F}$

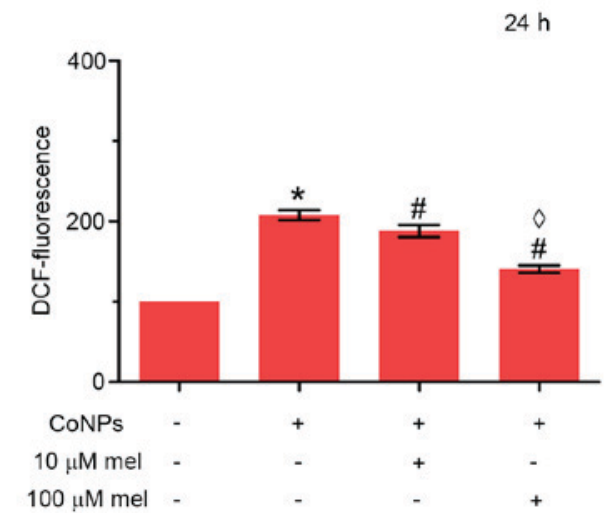

E

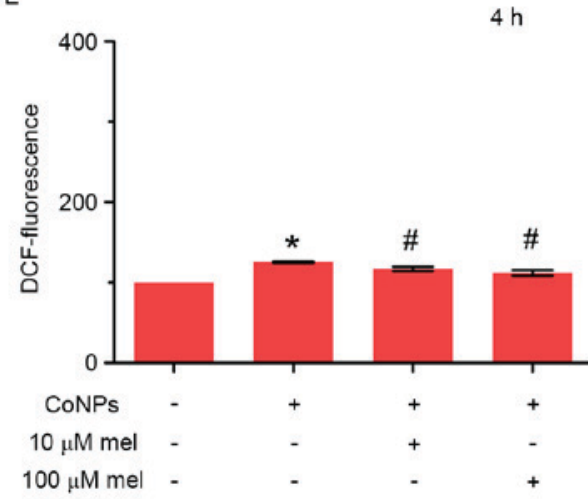

G

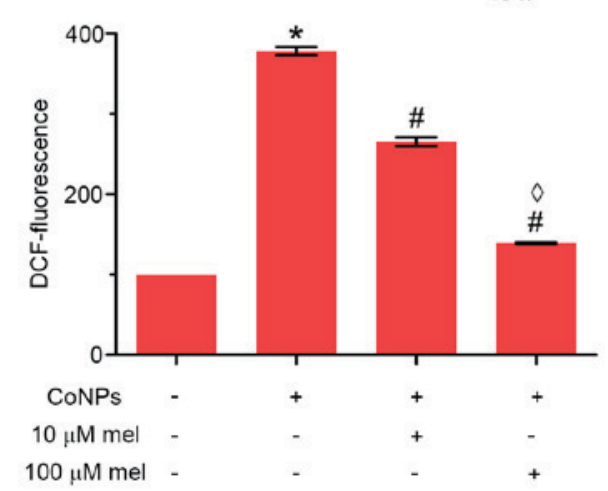

Figure 6. ROS generation following treatment with CoNPs was analyzed by using dichlorofluorescin diacetate. Representative microphotographs (magnification, $\mathrm{x} 40$ ) demonstrating CoNP-induced ROS generation in NRK cells treated with (A) control, (B) $100 \mu \mathrm{M} \mathrm{CoNPs,} \mathrm{(C)} 100 \mu \mathrm{M}$ CoNPs $+10 \mu \mathrm{M}$ melatonin and (D) $100 \mu \mathrm{M}$ CoNPs $+100 \mu \mathrm{M}$ melatonin (24 h). Quantified results demonstrating the percentage changes in ROS generation in different treatment groups when treated for (E) 4, (F) 24 and (G) 48 h. " $\mathrm{P}<0.05$ vs. control, ${ }^{~} \mathrm{P}<0.05$ vs. CoNPs group and ${ }^{\circ} \mathrm{P}<0.05$ vs. $10 \mu \mathrm{M}$ melatonin. ROS, reactive oxygen species; CoNPs, cobalt nanoparticles; mel, melatonin; DCF, dichlorofluorescein.

group, which may lead to the inhibition of downstream signaling events and subsequent inhibition of apoptosis induced by CoNPs.

Nanoparticle-induced DNA damage that is initiated by ROS has been previously reported (36), and the results of the comet assay in the current study confirmed that CoNPs are capable of generating ROS, which leads to oxidative DNA damage. Significantly increased levels of DNA damage were observed after 24 and $48 \mathrm{~h}$, and melatonin treated groups significantly reduced DNA damage compared with the CoNP-only group at 24 and $48 \mathrm{~h}$. In order to strengthen these results, the presence of DSBs was analyzed by immunostaining of $\gamma \mathrm{H} 2 \mathrm{AX}$, which is utilized as an early indicator for DSBs and is a highly specific marker. The results indicated that a significant percentage of cells treated with CoNPs exhibited DSBs, consistent with the results of the comet assay. However, after $48 \mathrm{~h}$ the foci counts were reduced compared with the $24 \mathrm{~h}$, which indicated that the assay highlighted earlier DNA damage. Furthermore, this phenomenon may also be explained by DNA repair mechanisms and cell death.

Previous studies have indicated that CoNP-induced toxicity is closely associated with oxidative stress $(37,38)$. Intracellular ROS were considered to be the primary factor involved in cytotoxicity and genotoxicity. Generation of excess ROS leads to damage of the mitochondria, lysosomes and the nucleus, and ultimately leads to the activation of the apoptotic pathway (39). Melatonin and its metabolites have been reported to function as antioxidants (40) and are considered to be efficient free radical scavengers that have the ability to quench a variety of free radicals, including hydrogen peroxide radicals $\left(\mathrm{H}_{2} \mathrm{O}_{2}\right)$, superoxide radicals $(. \mathrm{OOH})$ and hydroxyl radicals $(. \mathrm{OH})$. In the present study, CoNPs significantly increased the generation of ROS, while melatonin treatment significantly alleviated this increase. Furthermore, previous studies have demonstrated that the activation of certain antioxidant enzymes may be responsible for the antioxidant effect of melatonin $(41,42)$. These results indicate that melatonin may exhibit a potent antioxidant function, leading to the deactivation of ROS.

The results of the present study indicated that most damage was attenuated when treated with $100 \mu \mathrm{M}$ melatonin after $24 \mathrm{~h}$. Notably, even at a low concentration of melatonin, ROS levels were significantly reduced, which indicated that melatonin exhibits potent antioxidant action. However, the results also indicated that an ROS-independent mechanism may exist, as rapid quenching of free radicals was observed, while cytotoxicity and genotoxicity remained.

Evidence indicates that melatonin acts as an antioxidant against metal ions, exhibiting powerful protective effects against various metal ions, including $\mathrm{Al}^{3+}, \mathrm{Zn}^{2+}, \mathrm{Cu}^{2+}, \mathrm{Mn}^{2+}$, $\mathrm{Mg}^{2+}$ and $\mathrm{Fe}^{2+}$ (33). However, information regarding the effect of melatonin against nanoparticles is limited. In 1958, 
the indolamine melatonin was identified for the first time following purification and identification in bovine serum pineal derivatives by Lerner (43). Subsequent investigation has confirmed its potent antioxidant ability, and, in a variety of free radical-induced diseases, melatonin exhibits beneficial effects in terms of treatment and prevention (40). In addition, melatonin has also been reported to protect against metal-induced oxidative stress due to its free radical scavenging effects, the activation of antioxidant enzymes and metal chelation $(33,44)$. Previous studies have demonstrated that the antioxidant ability of melatonin is superior to other traditional antioxidants, such as vitamin $\mathrm{C}$ and vitamin $\mathrm{E}$ with limited antioxidant ability, which are unable to provide guidance for clinical medication $(19,20)$. Melatonin exhibits desirable properties, for example, it is ubiquitous, versatile, readily available and nontoxic (45). In the present study, melatonin protected NRK cells from CoNP-induced cytotoxicity and genotoxicity in vitro by reducing oxidative stress. These results may contribute to the development of novel strategies to reduce complications associated with nanoparticles released from MoM implants.

In conclusion, the results of the current study have indicated that exposure of NRK cells to CoNPs led to cytotoxicity and genotoxicity, and melatonin ameliorated these effects. These results demonstrate that melatonin may have potential as a therapeutic agent for CoNP-induced cytotoxicity and genotoxicity. The aim of the present study was to elucidate the adverse biological consequences of metal nanoparticles released from hip implants, and provide a potential method for reducing the adverse effects associated with these metal particles.

\section{Acknowledgements}

The present study was supported by the Natural Science Foundation of Jiangsu Province (grant no. BK20150399).

\section{References}

1. Akbar M, Brewer JM and Grant MH: Effect of chromium and cobalt ions on primary human lymphocytes in vitro. J Immunotoxicol 8: 140-149, 2011.

2. Hasegawa M, Yoshida K, Wakabayashi H and Sudo A: Cobalt and chromium ion release after large-diameter metal-on-metal total hip arthroplasty. J Arthroplasty 27: 990-996, 2012.

3. Liao Y, Hoffman E, Wimmer M, Fischer A, Jacobs J and Marks L: CoCrMo metal-on-metal hip replacements. Phys Chem Chem Phys 15: 746-756, 2013.

4. Tower SS: Arthroprosthetic cobaltism: Neurological and cardiac manifestations in two patients with metal-on-metal arthroplasty: A case report. J Bone Joint Surg Am 92: 2847-2851, 2010.

5. Gilbert CJ, Cheung A, Butany J, Zywiel MG, Syed K, McDonald M, Wong F and Overgaard C: Hip pain and heart failure: The missing link. Can J Cardiol 29: 639.e1-e2, 2013.

6. Oldenburg M, Wegner R and Baur X: Severe cobalt intoxication due to prosthesis wear in repeated total hip arthroplasty. J Arthroplasty 825: e15-e20, 2009.

7. Posada OM, Gilmour D, Tate RJ and Grant MH: CoCr wear particles generated from $\mathrm{CoCr}$ alloy metal-on-metal hip replacements, and cobalt ions stimulate apoptosis and expression of general toxicology-related genes in monocyte-like U937 cells. Toxicol Appl Pharmacol 281: 125-135, 2014.

8. Zhao J, Bowman L, Magaye R, Leonard SS, Castranova V and Ding M: Apoptosis induced by tungsten carbide-cobalt nanoparticles in JB6 cells involves ROS generation through both extrinsic and intrinsic apoptosis pathways. Int J Oncol 42: $1349-1359,2013$
9. Ladon D, Doherty A, Newson R, Turner J, Bhamra M and Case CP: Changes in metal levels and chromosome aberrations in the peripheral blood of patients after metal-on-metal hip arthroplasty. J Arthroplasty 19 (8 Suppl 3): S78-S83, 2004.

10. Papageorgiou I, Brown C, Schins R, Singh S, Newson R, Davis S, Fisher J, Ingham E and Case CP: The effect of nanoand micron-sized particles of cobalt-chromium alloy on human fibroblasts in vitro. Biomaterials 28: 2946-2958, 2007.

11. Patlolla A, Patlolla B and Tchounwou P: Evaluation of cell viability, DNA damage, and cell death in normal human dermal fibroblast cells induced by functionalized multiwalled carbon nanotube. Mol Cell Biochem 338: 225-232, 2010.

12. Jomova $\mathrm{K}$ and Valko $\mathrm{M}$ : Advances in metal-induced oxidative stress and human disease. Toxicology 283: 65-87, 2011.

13. Alarifi S, Ali D, Y AO, Ahamed M, Siddiqui MA and Al-Khedhairy AA: Oxidative stress contributes to cobalt oxide nanoparticles-induced cytotoxicity and DNA damage in human hepatocarcinoma cells. Int J Nanomedicine 8: 189-199, 2013.

14. Bazwinsky-Wutschke I, Bieseke L, Mühlbauer E and Peschke E: Influence of melatonin receptor signalling on parameters involved in blood glucose regulation. J Pineal Res 56: 82-96, 2014.

15. Belforte NA, Moreno MC, de Zavalia N, Sande PH, Chianelli MS, Keller Sarmiento MI and Rosenstein RE: Melatonin: A novel neuroprotectant for the treatment of glaucoma. J Pineal Res 48: 353-364, 2010

16. Rodella LF, Favero G, Rossini C, Foglio E, Reiter RJ and Rezzani R: Endothelin-1 as a potential marker of melatonin's therapeutic effects in smoking-induced vasculopathy. Life Sci 87: 558-564, 2010.

17. Sakaguchi K, Itoh MT, Takahashi N, Tarumi W and Ishizuka B: The rat oocyte synthesises melatonin. Reprod Fertil Dev 25: 674-682, 2013.

18. Alvarez-Garcia V, González A, Alonso-González C, Martínez-Campa $\mathrm{C}$ and Cos S: Melatonin interferes in the desmoplastic reaction in breast cancer by regulating cytokine production. J Pineal Res 52: 282-290, 2012.

19. Sofic E, Rimpapa Z, Kundurovic Z, Sapcanin A, Tahirovic I, Rustembegovic A and Cao G: Antioxidant capacity of the neurohormone melatonin. J Neural Transm (Vienna) 112: 349-358, 2005.

20. Martin M,Macias M,Escames G,León J and Acuña-Castroviejo D: Melatonin but not vitamins $\mathrm{C}$ and $\mathrm{E}$ maintains glutathione homeostasis in t-butyl hydroperoxide-induced mitochondrial oxidative stress. FASEB J 14: 1677-1679, 2000.

21. Emamgholipour S, Hossein-Nezhad A, Sahraian MA, Askarisadr F and Ansari M: Evidence for possible role of melatonin in reducing oxidative stress in multiple sclerosis through its effect on SIRT1 and antioxidant enzymes. Life Sci 145: 34-41, 2016.

22. Wan R, Mo Y, Zhang X, Chien S, Tollerud DJ and Zhang Q: Matrix metalloproteinase- 2 and -9 are induced differently by metal nanoparticles in human monocytes: The role of oxidative stress and protein tyrosine kinase activation. Toxicol Appl Pharmacol 233: 276-285, 2008.

23. Uzar NK, Abudayyak M, Akcay N, Algun G and Özhan G: Zinc oxide nanoparticles induced cyto- and genotoxicity in kidney epithelial cells. Toxicol Mech Methods 25: 334-339, 2015.

24. Tsaousi A, Jones E and Case CP: The in vitro genotoxicity of orthopaedic ceramic (A12O3) and metal ( $\mathrm{CoCr}$ alloy) particles. Mutat Res 697: 1-9, 2010.

25. Xu SC, He MD, Zhong M, Zhang YW, Wang Y, Yang L, Yang J, Yu ZP and Zhou Z: Melatonin protects against Nickel-induced neurotoxicity in vitro by reducing oxidative stress and maintaining mitochondrial function. J Pineal Res 49: 86-94, 2010.

26. Zhu H, Liu Y, Hong H, Wang W and Liu F: Protective effects of Zn2+ against cobalt nanoparticles and cobalt chloride-induced cytotoxicity of RAW 264.7cells via ROS pathway. Biochem Biophys Res Commun 486: 357-363, 2017.

27. Liu YK, Yang HW, Wang MH, Wang W, Liu F and Yang HL: $\mathrm{N}$-acetylcysteine attenuates cobalt nanoparticle-induced cytotoxic effects through inhibition of cell death, reactive oxygen species-related signaling and cytokines expression. Orthop Surg 8: 496-502, 2016

28. Wang D, Liu Y, Xu X, Liu H and Fan L: Cobalt nanoparticle-induced cytotoxicity and up-regulation of p53 expression on nrk cells in vitro. J Comput Theor Nanosci 12: 4473-4477, 2015.

29. Wang S, Liu F, Zeng Z, Yang H and Jiang H: The protective effect of bafilomycin A1 against cobalt nanoparticle-induced cytotoxicity and aseptic inflammation in macrophages in vitro. Biol Trace Elem Res 169: 94-105, 2016. 
30. Qiao H, Li L, Qu ZC and May JM: Cobalt-induced oxidant stress in cultured endothelial cells: Prevention by ascorbate in relation to HIF-1alpha. Biofactors 35: 306-313, 2009.

31. Liu Y, Hong H, Lu X, Wang W, Liu F and Yang H: L-ascorbic acid protected against extrinsic and intrinsic apoptosis induced by cobalt nanoparticles through ROS attenuation. Biol Trace Elem Res 175: 428-439, 2017.

32. Susa N, Ueno S, Furukawa Y, Ueda J and Sugiyama M: Potent protective effect of melatonin on chromium(VI)-induced DNA single-strand breaks, cytotoxicity, and lipid peroxidation in primary cultures of rat hepatocytes. Toxicol Appl Pharmacol 144: 377-384, 1997.

33. Romero A, Ramos E, de Los Ríos C, Egea J, Del Pino J and Reiter RJ: A review of metal-catalyzed molecular damage: Protection by melatonin. J Pineal Res 56: 343-370, 2014.

34. Krueger A, Baumann S, Krammer PH and Kirchhoff S: FLICE-inhibitory proteins: Regulators of death receptor-mediated apoptosis. Mol Cell Biol 21: 8247-8254, 2001.

35. Janicke RU, Sprengart ML, Wati MR and Porter AG. Caspase-3 is required for DNA fragmentation and morphological changes associated with apoptosis. J Biol Chem 273: 9357-9360, 1998.

36. AshaRani PV, Low Kah Mun G, Hande MP and Valiyaveettil S: Cytotoxicity and genotoxicity of silver nanoparticles in human cells. ACS Nano 3: 279-290, 2009.

37. Behl B, Papageorgiou I, Brown C, Hall R, Tipper JL, Fisher J and Ingham E: Biological effects of cobalt-chromium nanoparticles and ions on dural fibroblasts and dural epithelial cells. Biomaterials 34: 3547-3558, 2013.
38. Senapati VA, Jain AK, Gupta GS, Pandey AK and Dhawan A: Chromium oxide nanoparticle-induced genotoxicity and p53-dependent apoptosis in human lung alveolar cells. J Appl Toxicol 35: 1179-1188, 2015.

39. Ott M, Gogvadze V, Orrenius $S$ and Zhivotovsky B: Mitochondria, oxidative stress and cell death. Apoptosis 12: 913-922, 2007.

40. Karaaslan C and Suzen S: Antioxidant properties of melatonin and its potential action in diseases. Curr Top Med Chem 15: 894-903, 2015

41. Jimenez-Ortega V, Cano P, Cardinali DP and Esquifino AI: 24-Hour variation in gene expression of redox pathway enzymes in rat hypothalamus: Effect of melatonin treatment. Redox Rep 14: 132-138, 2009.

42. Rodriguez C, Mayo JC, Sainz RM, Antolín I, Herrera F, Martín V and Reiter RJ: Regulation of antioxidant enzymes: A significant role for melatonin. J Pineal Res 36: 1-9, 2004.

43. Lerner AB, Case JD, Takahashi Y, Lee TH and Mori W: Isolation of melatonin, the pineal gland factor that lightens melanocytes1. J Am Chem Soci 80: 2587, 1958

44. Parmar P, Limson J, Nyokong T and Daya S: Melatonin protects against copper-mediated free radical damage. J Pineal Res 32: 237-242, 2002.

45. Galano A, Tan DX and Reiter RJ: Melatonin as a natural ally against oxidative stress: A physicochemical examination. J Pineal Res 51: 1-16, 2011. 